\title{
Properties of Zinc Releasing Surfaces for Clinical Applications
}

\author{
G. Lusvardi, G. Malavasi, L. Menabue, \\ M. C. Menziani, A. Pedone and U. Segre \\ University of Modena and Reggio Emilia, Via Campi 483 \\ 41100 Modena, Italy \\ V. Aina, A. Perardi And C. Morterra \\ Department of Chemistry IFM and Centre of Excellence NIS \\ Via P. Giuria 7, 10125 Torino, Italy \\ F. Boccafoschi, S. Gatti, M. Bosetti and M. Cannas* \\ Department of Clinical and Experimental Medicine, University of Eastern \\ Piedmont, Via Solaroli 17, 28100 Novara, Italy
}

\begin{abstract}
Two series of glasses of general formula (2-p) $\mathrm{SiO}_{2} \cdot 1.1 \mathrm{Na}_{2} \mathrm{O} \cdot \mathrm{CaO} \cdot p \mathrm{P}_{2} \mathrm{O}_{5} \cdot x \mathrm{ZnO}(p=0.10,0.20 ; x=0.0,0.16,0.35$, and 0.78$)$ have been analyzed for physico-chemical surface features before and after contact with simulated body fluid, morphological characteristics, and osteoblastlike cells behavior when cultured on them. The resulted good cell adhesion and growth, along with nonsignificant changes of the focal contacts, allow the authors to indicate HZ5 and HP5Z5 glasses as the ones having optimal ratio of $\mathrm{Zn} / \mathrm{P}$ to maintain acceptable cell behavior, comparable to the bioactive glass $\left(\right.$ Bioglass ${ }^{\circledR}$ ) used as a control; results are also rationalized by means of three-dimensional models derived by molecular dynamic simulations, with decomposition and conversion rates optimized with respect to the parent Hench's Bioglass ${ }^{\circledR}$.
\end{abstract}

KEY WORDS: bioactive glass, zinc, osteoblasts, cell adhesion and proliferation, focal contacts, molecular dynamics.

\footnotetext{
*Author to whom correspondence should be addressed. E-mail: cannas@med.unipmn.it Figures 6-8, 12 and 13 appear in color online: http://jba.sagepub.com
}

JOURNAL OF BIOMATERIALS APPLICATIONS Volume 22 - May 2008 


\section{INTRODUCTION}

R ioglass (Hench's Bioglass 45S5: 45\% $\mathrm{SiO}_{2}, 24.5 \% \mathrm{Na}_{2} \mathrm{O}, 24.5 \%$ $3 \mathrm{CaO}, 6 \%$ P2O5) may be considered a paradigm for bioactive materials [1]. The high rate of formation of hydroxy-carbonate apatite (HA) at its surface is the essential condition that elicits the interaction with tissues and induces both intrinsic repair and regenerative potential. This implies an active contribution of the biomaterial to the cell cycle that controls cell proliferation and differentiation. A major disadvantage is connected to its high solubility: most of the released ions might be transported away from the implantation site surroundings by the body fluid before new bone can form. Besides, the mechanical properties of bioglass are not completely adequate for significant load bearing applications [2].

Control of surface reactions and, therefore, of biodegradation and bioactivity of implanted materials can be achieved by rational design of glass compositions. In fact, by varying the chemical nature and concentration of the bioglass constituents (and dopants), new important mechanical and biological properties for specific clinical applications can be tailored [3].

It has recently been demonstrated that the release of small concentration of zinc $(\mathrm{Zn})$ incorporated into an implant material could promote bone formation around the implant and accelerate recovery of the patients [4-6]. Materials containing $\mathrm{Zn}$ promote the expression and maintenance of the osteoblastic phenotype, and $\mathrm{Zn}$ present at resorptive sites is connected with the recruitment of osteoblastic cells and bone renewal $[7,8]$.

Moreover, $\mathrm{Zn}$ is well known for its antimicrobial properties, and it is a constituent of the denture adhesive as a cross-linking agent to promote adhesion [9]. Still, it is important to control $\mathrm{Zn}$ releasing rate in order to prevent adverse reactions and to optimize the glass composition to reduce glass degradation without affecting HA deposition.

Several formulations of bioactive glasses doped with $\mathrm{Zn}$ have recently been obtained both by melting [10-12] and by sol-gel techniques [13], and their reactivity and potential bioactivity have been studied in vitro with respect to ion release and HA forming ability as a result of contact with simulated body fluid (SBF) [14].

Insights into the structural determinants for the observed macroscopic behavior, obtained by means of molecular dynamics (MD) simulation studies [10-12,15], allowed the authors to design and select some Zn containing glasses to be used for further systematic investigations, the results of which are presented in this work. 
Thus, the biocompatibility of two series of glasses, prepared by enriching the parent bioglass with different percentages of phosphorous (P) and/or Zn, has been evaluated in vitro in both acellular and cellular environments. In particular, the results deriving from monitoring the evolution of the interaction between the glass surface and the surrounding SBF fluid, as well as from studying adhesion and proliferation of osteoblast-like cells, are highlighted.

Finally, an interpretation at atomic level of the structural role played by the different constituents on in vitro bioactivity is provided by means of the structural models obtained from MD studies.

\section{MATERIALS AND METHODS}

\section{Materials}

The bioactive glass of molar composition $46.2 \% \mathrm{SiO}_{2}, 26.9 \% \mathrm{CaO}$, $24.325 \mathrm{Na}_{2} \mathrm{O}$, and 2.6\% $\mathrm{P}_{2} \mathrm{O}_{5}$ (named $\mathrm{H}$ from now on), was developed and extensively studied by Hench and coworkers. From this starting point, two series of glasses were obtained: in the first one, the glasses named HZ5, HZ10, and HZ20 were prepared by adding to the $\mathrm{H}$ glass 3.8, 7.8, and $15.9 \% \mathrm{~mol} \mathrm{ZnO}$, respectively; in the second series, a P-rich glass termed HP5 (molar composition $43.8 \% \mathrm{SiO}_{2}, 5 \% \mathrm{P}_{2} \mathrm{O}_{5}, 26.9 \% \mathrm{CaO}$, $24.325 \mathrm{Na}_{2} \mathrm{O}$ ) was modified by addition of $3.9 \% \mathrm{~mol} \mathrm{ZnO} \mathrm{(HP5Z5)} \mathrm{and}$ $8.0 \% \mathrm{~mol} \mathrm{ZnO}$ (HP5Z10), respectively, which replace an equivalent percentage of $\mathrm{SiO}_{2}$.

Raw materials $\left(\mathrm{SiO}_{2}, \mathrm{CaCO}_{3}, \mathrm{Na}_{2} \mathrm{CO}_{3}, \mathrm{Na}_{3} \mathrm{PO}_{4} \cdot 12 \mathrm{H}_{2} \mathrm{O}\right.$, and $\left.\mathrm{ZnCO}_{3}\right)$ were melted in a platinum crucible for $2 \mathrm{~h}$ at $1550^{\circ} \mathrm{C}$. The melt was quickly cooled between two graphite sheets to avoid undesired crystallization phenomena and to obtain thin plane slabs that were annealed at $450^{\circ} \mathrm{C}$ for $4 \mathrm{~h}$ in order to release any residual internal stress. Slabs of $1 \mathrm{~cm}^{2}$ surface area were used for cellular tests. According to in vitro tests in a SBF proposed by Kokubo and coworkers [14], an amount of thin slab was poured in an agate mortar and milled to produce particles in the $250<\emptyset<50 \mu \mathrm{m}$ size range to be used for acellular tests. In order to evaluate the surface behavior, particles of size range $\emptyset<2 \mu \mathrm{m}$ were also produced for IR and surface area tests.

\section{Surface Characterization}

For surface area measurements and collection of IR data, powdery glass samples $(\varnothing<2 \mu \mathrm{m})$ were soaked in a simple aqueous solution containing $0.05 \mathrm{M}$ tris-hydroxylamino methane (TRIS), with a $\mathrm{pH}$ 7.8. 
In this way, glass dissolution remained the only source of ions for the precipitation of salts on the surface of the glass. Solid mass/liquid volume ratio for these samples was $0.075 \mathrm{~g} / 50 \mathrm{~mL}$, and soaking took place at RT, by stirring for $1,6,24$, and $48 \mathrm{~h}$.

\section{IR}

Infrared spectra were recorded by a Bruker IFS 28 FTIR Spectrometer, equipped with both MCT and DTGS detector. Powdered samples, either pure (for in situ studies) or mixed with $\mathrm{KBr}$, were pressed in the form of self-supporting pellets. For in situ thermal treatments of pure glass pellets and probe molecules adsorption on activated samples, a home-made quartz infrared cell was connected to a conventional vacuum line (residual pressure $\approx 10^{-5}$ Torr). All IR spectra were recorded at beam-temperature (BT), i.e., the temperature reached by (white) pellets under the IR beam. BT is estimated to be some $20-30 \mathrm{~K}$ higher than actual room temperature (RT).

\section{Surface Area Measurements}

Specific surface area of the samples was determined according to the BET model [16], by $\mathrm{N}_{2}$ adsorption at $77 \mathrm{~K}$, using an automatic gasvolumetric apparatus ASAP 2010 (Micromeritics).

\section{In vitro Tests in SBF}

All samples were soaked in protein-free and acellular SBF $(250 \mathrm{mg}$ of glass powder $250<\varnothing<500 \mu \mathrm{m}$ in $50 \mathrm{~mL}$ of SBF) with ion concentrations and $\mathrm{pH}$ nearly equal to those of human blood plasma. The SBF solution was prepared according to Kokubo et al. [14]. The soaking was carried out at $37^{\circ} \mathrm{C}$, under continuous stirring for $1,10,24 \mathrm{~h}$ and $4,15,30$, and 60 days. Since the ratio of the exposed surface to the volume of the SBF solution is expected to affect the reaction, a constant solid mass/liquid volume ratio $(0.25 \mathrm{~g} / 50 \mathrm{~mL})$ was maintained.

\section{SEM-EDS and XRD Analysis}

After soaking in SBF, the wet samples were analyzed by means of X-ray diffraction (Philips PW3710-based automated diffractometer, using Ni-filtered $\mathrm{Cu} \mathrm{K} \alpha$ radiation $\lambda=1.54060 \AA$ ), scanning electron microscopy (SEM, Philips PSEM 500 XL-40), and energy-dispersive spectrometry (EDS, X-EDS EdaxPV9900) to verify morphological and 
compositional modifications of the surfaces and to check HA precipitation.

\section{Leaching Tests}

The amount of $\mathrm{Na}, \mathrm{Ca}, \mathrm{Si}, \mathrm{Zn}$, and $\mathrm{P}$ present in the SBF solution after different soaking times was measured by inductively coupled plasma (ICP) spectrometer (Perkin Elmer Optima 4200 DV) equipped with ultrasonic nebulizer for trace elements. Each value reported is an average of four measurements. For comparative purposes, the pure SBF solution was also analyzed.

\section{Cell Culture Tests}

Cytocompatibility tests were performed on glass slab surface of average $1 \mathrm{~cm}^{2}$ using murine bone pre-osteoblast cell line (MC3T3-E1 subclone 4, ATCC CRL-2593), cultured in Iscove's modified Dulbecco's medium (IMDM) supplemented with $10 \%$ (v/v) fetal bovine serum (FBS, Sigma), $100 \mathrm{U} / \mathrm{mL}$ penicillin, $100 \mu \mathrm{L}$ streptomycin, and $0.03 \%$ L-glutammine at $37^{\circ} \mathrm{C}$ in $95 \%$ air $/ 5 \% \mathrm{CO}_{2}$.

MC3T3-E1 adhesion and proliferation was assessed by seeding $2 \times 10^{4}$ cells $/ \mathrm{cm}^{2}$; cells cultured on cell culture grade polystyrene have been used as positive control. After different incubation times $(3,6,12$, 24 , and $48 \mathrm{~h}$ ) the number of adherent cells and their morphology have been studied by fluorescence microscopy, because the tested materials were not usable for normal transmitted light microscopy. After 3 and $6 \mathrm{~h}$ (cell adhesion) and 12, 24, and $48 \mathrm{~h}$ (cell proliferation), osteoblast-like cells on the tested materials were rinsed in PBS, fixed for $20 \mathrm{~min}$ at $60^{\circ} \mathrm{C}$ and stained for $5 \mathrm{~min}$ in a $0.025 \%$ Acridine Orange solution, a nucleic acid staining [17]. Cell morphology and cell number on each material have been evaluated using a fluorescent microscope Aristoplan (Leitz Leica, Milano, Italy). Cell number has been evaluated on a surface of $0.1715 \mathrm{~mm}^{2}$ using $25 \mathrm{X}$ microscope magnification and results were reported as mean \pm standard error of 10 random fields obtained from seven different experiments $(n=70)$.

\section{Focal Contacts}

Cells have been cultured on bioactive glasses for $24 \mathrm{~h}$, fixed in formaldehyde $3.7 \%$ for $30 \mathrm{~min}$ and then labeled with anti-vinculin antibody (Oncogene, Italy) FITC conjugated (Santa Cruz, Italy) and phalloidin-TRITC conjugated (Sigma, Italy). Focal contacts have been 
observed by confocal microscopy (Leica, TGS 4D) at a $40 \times$ magnification, $(488 \mathrm{~nm}$ excitation $/ 514 \mathrm{~nm}$ emission for vinculin-FITC and $550 \mathrm{~nm}$ excitation $/ 580 \mathrm{~nm}$ emission for phalloidin-TRITC).

\section{Statistical Analysis}

Statistical analysis of data was carried out using the SPSS software for Windows. The Bonferroni test was performed taking $p<0.05$, as the minimum level of significance.

\section{Molecular Dynamics Simulations}

Molecular dynamics simulations were performed with the DL_POLY ${ }^{\circledR}$ [18] program, using Cerius2 ${ }^{\circledR}$ [19] as a graphical interface. The computational procedure is reported in detail in the cited earlier work [15].

Periodic boundary conditions were applied to the cubic boxes containing, on average, 1400 atoms. Input structures were melted at nominal temperatures of $12,000 \mathrm{~K}$ and the quenching scheme used to bring the system to $300 \mathrm{~K}$ corresponds to a cooling rate of $\approx 4.6 \times 10^{13} \mathrm{~K} / \mathrm{s}$. A time step of $2 \mathrm{fs}$ was used. The long-range electrostatic potential was evaluated by Ewald summation method with the cutoff distance set at $12 \AA$ and precision set to $10^{-6}$. The shortrange cutoff distance was set at $7.6 \AA$. The short range interactions between $\mathrm{Si}-\mathrm{O}, \mathrm{Zn}-\mathrm{O}, \mathrm{P}-\mathrm{O}, \mathrm{Na}-\mathrm{O}$, and $\mathrm{Ca}-\mathrm{O}$ were modeled by a fourrange Buckingham potential. [20]. A three body screened Vessal potential [21] was applied to the O-Si-O bond angle. Data collection was performed every 50 time steps during the last 10,000 time steps of the whole MD runs.

\section{RESULTS}

\section{Surface Characterization}

Specific surface area of bioactive glasses containing increasing amounts of $\mathrm{Zn}$ has been measured before and after soaking in TRISbuffered solution (Figure 1). It can be noted that $\mathrm{H}$ glass, the reference glass without $\mathrm{Zn}$, undergoes a very high increase of surface area already in the first hour of reaction (from $\approx 2 \mathrm{~m}^{2} / \mathrm{g}$ to $\approx 200 \mathrm{~m}^{2} / \mathrm{g}$ ). Zinc containing glasses develop a much smaller surface area, even for soaking times up to 2 days. Moreover, the increase of surface area declines with increasing Zn content. 


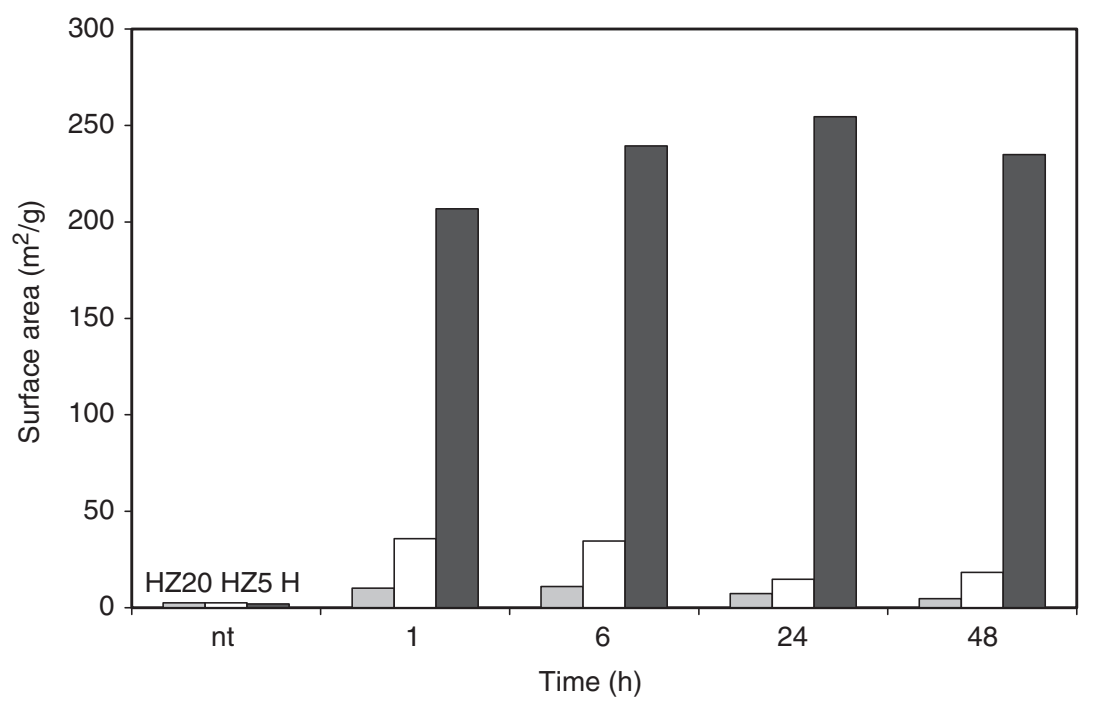

Figure 1. Specific surface area of powdered samples (starting grain size, $<26 \mu \mathrm{m}$ ) of the bioactive glasses H, HZ5, and HZ20, before and after soaking in TRIS-buffered solution for $1,6,24$, and 48 hours.

IR

Infrared spectra were recorded on samples of bioactive glass with and without Zn (H, HZ5, and HZ20), before and after soaking in TRIS solution for 1, 6h and 1 day (Figure 2). On non-reacted glasses, the large envelope of silica bands detected around $1020 \mathrm{~cm}^{-1}$ shows a rather strong shoulder at $930 \mathrm{~cm}^{-1}$, indicating a large number of non-bridging oxygens bound to $\mathrm{Na}^{+}$or $\mathrm{Ca}^{2+}$ countercations.

During the course of reaction the shoulder disappears, as cations are leached from the material and a silica-rich layer is formed at the surface. At the same time, the main band shifts to higher frequencies, due to the growth of the phosphate component contribution, while other smaller phosphate bands appear around 500 and $600 \mathrm{~cm}^{-1}$.

In the $\mathrm{H}$ glass (Figure 2a), the mentioned modifications are already evident after the first hour of soaking; on the other hand, in HZ20 (Figure 2c), they are not observed even after 1 day of reaction. Significantly, HZ5 (Figure 2b) represents an intermediate situation, where the $930 \mathrm{~cm}^{-1}$ shoulder is maintained until at least 1 day of reaction, but a gradual shift of up to about $20 \mathrm{~cm}^{-1}$ can be observed in the main band, together with the formation of other auxiliary phosphate bands at $\approx 500 \mathrm{~cm}^{-1}$. 

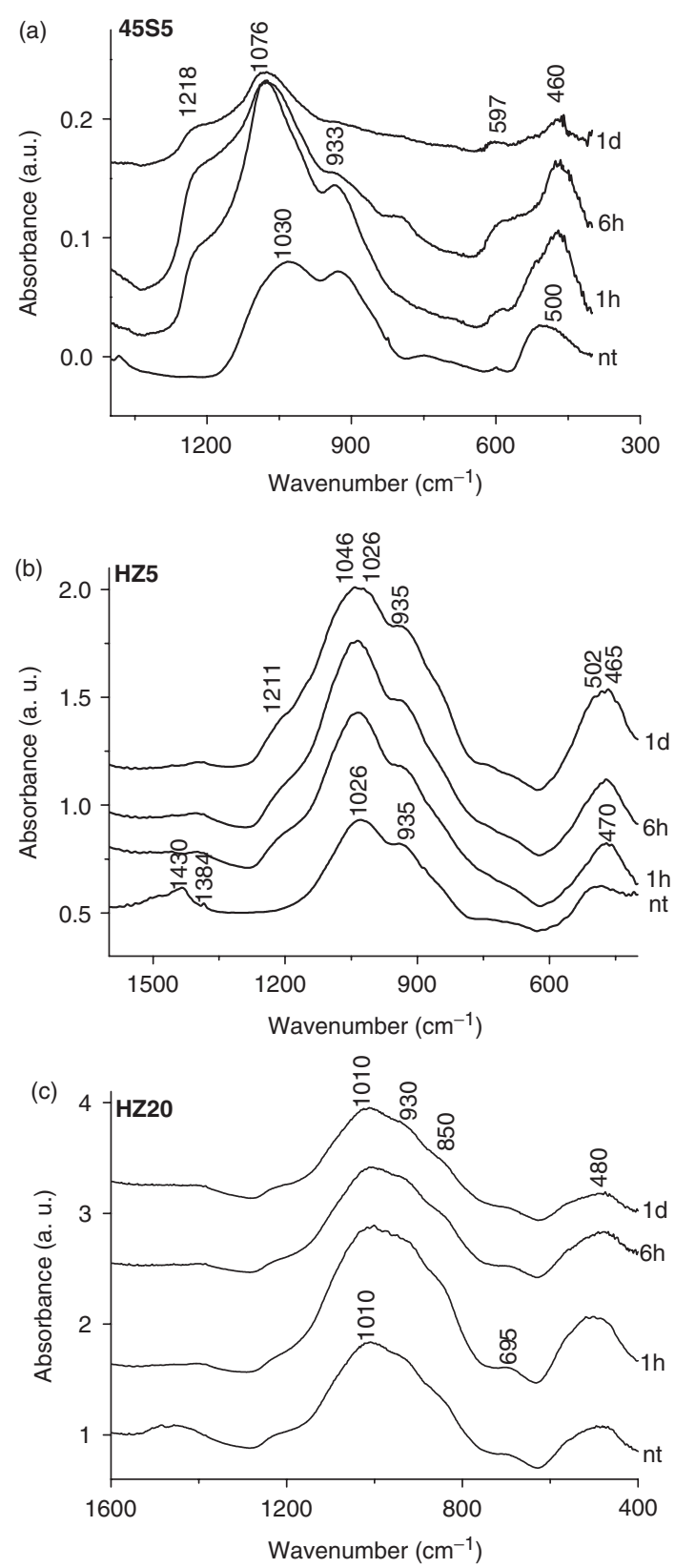

Figure 2. IR spectra of bioactive glasses H (45S5) (a), HZ5(b), and HZ20 (c) before and after soaking for $1,6 \mathrm{~h}$, and $1 \mathrm{~d}$ in TRIS solution (analysis on pellets prepared by mixing 1 part of powdered sample with 20 parts $\mathrm{KBr}$ ). 
The surface activity of solid samples can be investigated by in situ contact with selected probe molecules: here, water and carbon dioxide were allowed on HZ5 glass with the purpose of inducing carbonation of cationic surface sites [22]. Infrared spectra recorded after contact with the mentioned probe molecules show a single peak at $1463 \mathrm{~cm}^{-1}$, that suggests a prevailing presence of Na-based carbonates over Ca-based carbonates.

\section{Surface Area}

The data relative to surface area evolution turn out to be consistent with what indicated by in situ IR spectra of surface carbonation and as shown in Figure 3(a); Na-carbonates are typical of all non-reacted, Na-containing glasses. After the first hour of reaction, on $\mathrm{Zn}$-free $\mathrm{H}$ glass cations leaching has occurred, surface area has increased dramatically, and surface Ca-carbonates prevail, whereas after $6 \mathrm{~h}$ of soaking of the Zn-containing HZ5 glass samples, very little cations leaching has occurred and, consistently, the $1463 \mathrm{~cm}^{-1}$ peak of Na-carbonates is still present as a major component (Figure 3(b)). These observations constitute a hint of the reduced reactivity of $\mathrm{Zn}$-containing glasses and, in particular, confirm for these systems the scarce release, or even the surface accumulation, of sodium ions.

\section{In vitro Tests in SBF (SEM-EDS and XRD Analysis)}

EDS analyses carried out after 1-24 h of soaking in SBF on the glass surfaces of $\mathrm{Zn}$-free samples (H and HP5) and of samples containing small amounts of Zn (HZ5 and HP5Z5) revealed a decrease of sodium concentration with respect to the as-quenched glasses (Figure 4(B)). Calcium $(\mathrm{Ca})$ and $\mathrm{P}$ ions accumulate on the surface (Figure 4(A)) where their concentrations are higher than those measured on the same samples before soaking. After 4-15 days of SBF soaking, spherical particles mostly constituted of $\mathrm{Ca}$ and $\mathrm{P}$ are observed on the external layer. The $\mathrm{Ca} / \mathrm{P}$ molar ratio (calculated by peak area integration) is of $\approx 1.67$, corresponding to the value of $\mathrm{HA}\left[\mathrm{Ca}_{10}\left(\mathrm{PO}_{4}\right)_{6}(\mathrm{OH})_{2}\right]$; silicon $(\mathrm{Si})$ is still detected at the surfaces, not completely covered by HA particles. (Figure 4(B)).

The different layers are clearly identified in the Zn-rich glasses (HZ10 and HZ20) after longer soaking time (30-60 days). EDS spectra show that also these glasses become poorer in sodium after SBF soaking, but to a definitely lower extent with respect to the glasses with low concentration of $\mathrm{Zn}$ ions. The morphology of these surfaces is 

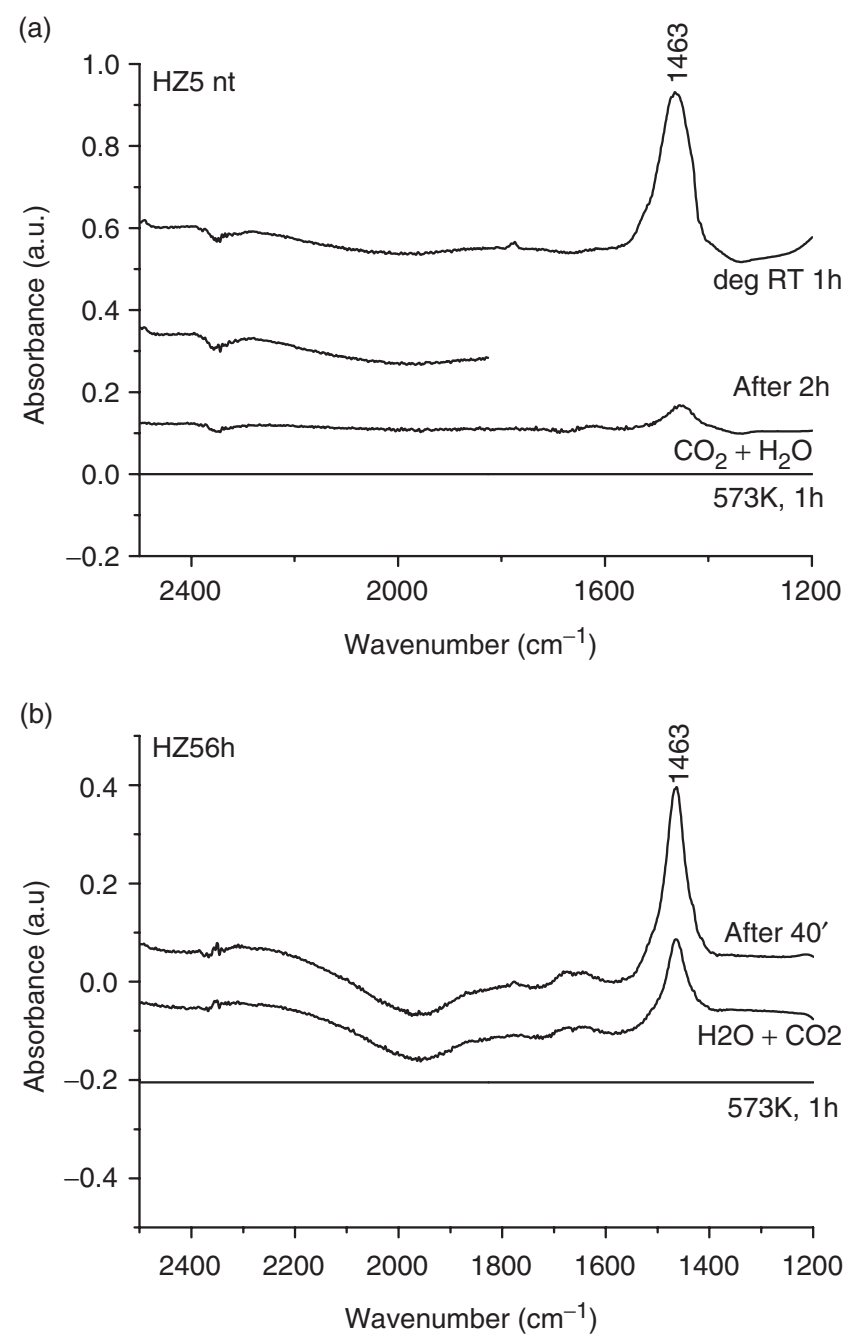

Figure 3. Carbonation with $\mathrm{CO}_{2}+\mathrm{H}_{2} \mathrm{O}$ of the bioactive glass $\mathrm{HZ} 5$ before (a), and after soaking for $6 \mathrm{~h}$ in TRIS solution (b). Differential absorbance IR spectra, performed in situ on pure sample pellets, were obtained by subtracting from raw spectra the background spectrum of samples thermally treated at $573 \mathrm{~K}$.

significantly different from the previously observed ones: the internal layer is mainly constituted of $\mathrm{Si}$, whereas high concentrations of $\mathrm{Ca}, \mathrm{P}$, and $\mathrm{Zn}$ ions are found in the external layer (Figure 5(A) and (B)). The $\mathrm{Ca} / \mathrm{P}$ molar ratio is close to 1 ; this value is lower with respect to the value 


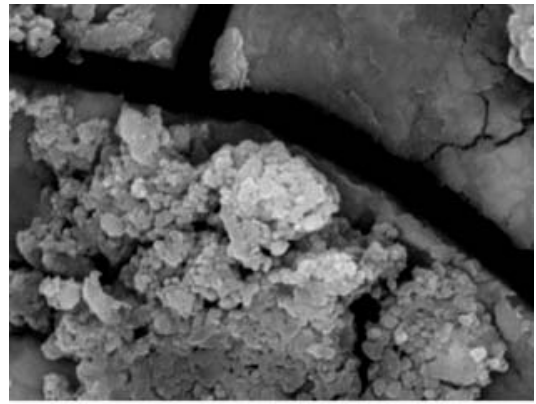

$-2 \mu \mathrm{m}$
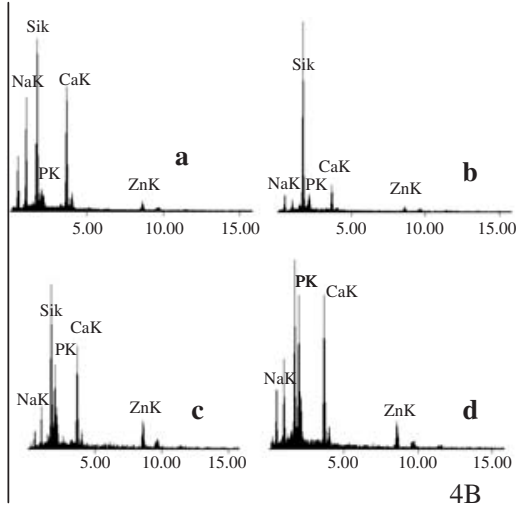

Figure 4. (A) Scanning electron micrograph of the HZ5 glass after soaking in SBF for 15d; (B) energy dispersive spectra of the HZ5 glass before and after 15d soaking in SBF: (a) before soaking; (b) internal layer after soaking; (c), and (d) external layer after soaking.

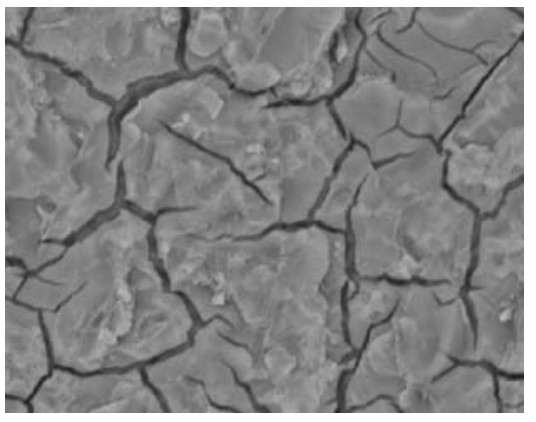

$5 \mu \mathrm{m}$

$5 \mathrm{~A}$

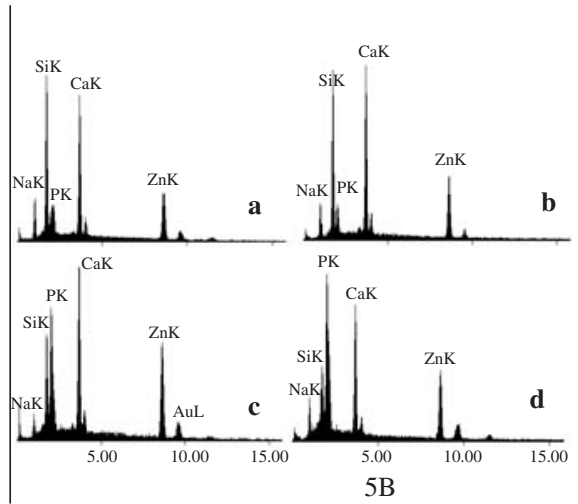

Figure 5. (A) Scanning electron micrograph of the HZ20 glass after soaking in SBF for 60d; (B) energy dispersive spectra of HZ20 glass before and after 60d soaking in SBF: (a) before soaking; (b) internal layer after soaking; (c), and (d) external layer after soaking.

of HA and, in fact, spherical particles characteristic of HA are, in this case, very sporadic and irregular. An intermediate behavior between that of high- and low-Zn containing glasses is exhibited by the HP5Z10 sample. In fact, after 30-60 days of SBF soaking, an external layer that can be attributed to $\mathrm{HA}$ is found to cover homogeneously the glass surface. 
Table 1. HA detection by XRD analysis as function of soaking time.

\begin{tabular}{lccc}
\hline Glass & $15 d$ & $30 d$ & $60 d$ \\
\hline$H$ & $X$ & $X$ & $X$ \\
HZ5 & $X$ & $X$ & $X$ \\
HZ10 & $O$ & $O$ & $X$ \\
HZ20 & $O$ & $O$ & $O$ \\
HP5 & $X$ & $X$ & $X$ \\
HP5Z5 & $X$ & $X$ & $X$ \\
HP5Z10 & $O$ & & $X$ \\
\hline (X=detected, O=no detected). &
\end{tabular}

\section{HP5}

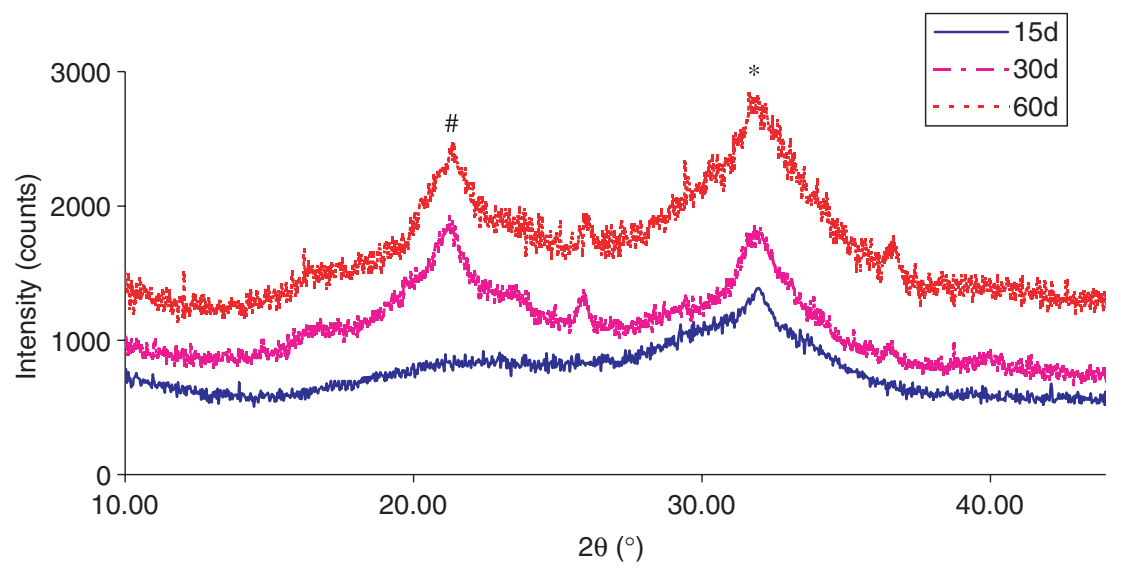

Figure 6. XRD patterns for HP5 powder glass after 15, 30, and 60d of SBF soaking. (\# silica gel, * HA).

These results are confirmed by means of XRD analysis performed on the soaking glass powders. After 15 days of SBF soaking the H, HZ5, HP5, and HP5Z5 samples (see Table 1) show the main peak characteristic of the presence of HA and a broad peak that can be attributed to $\mathrm{SiO}_{2}$ gel. (Figure 6). XRD analysis carried out on HP5Z10 glass powders detects the same behavior, though after longer time (30-60 days) (Figure 7).

\section{Leaching Tests}

The concentration $(\mathrm{mM})$ of species released from glass powders after various soaking times in the SBF solution has also been monitored. 


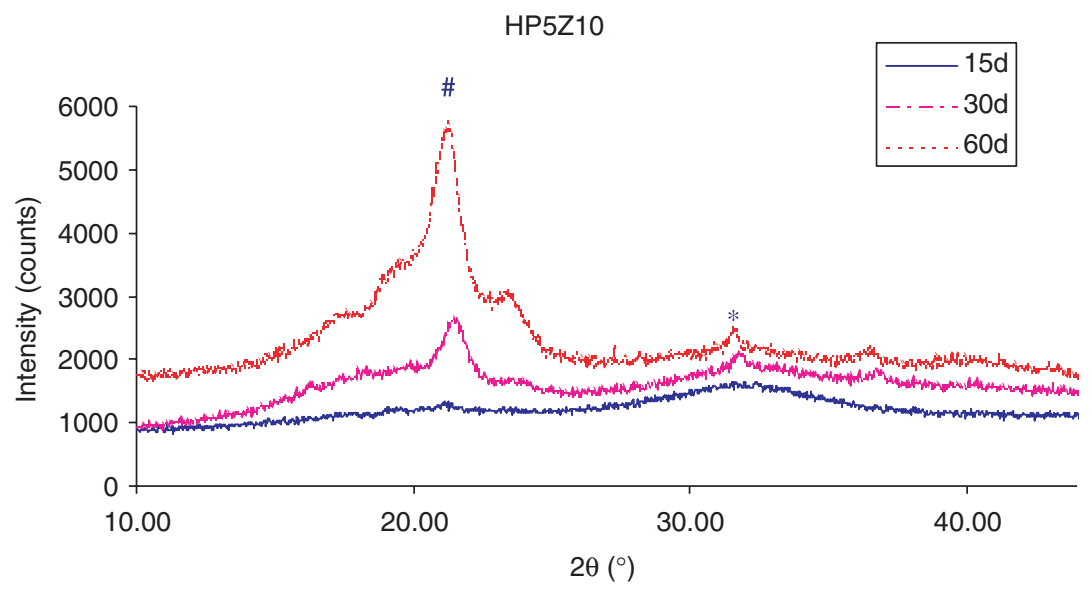

Figure 7. XRD patterns for HP5Z10 powder glass after 15, 30. and 60d of SBF soaking. (\# silica gel, * HA).

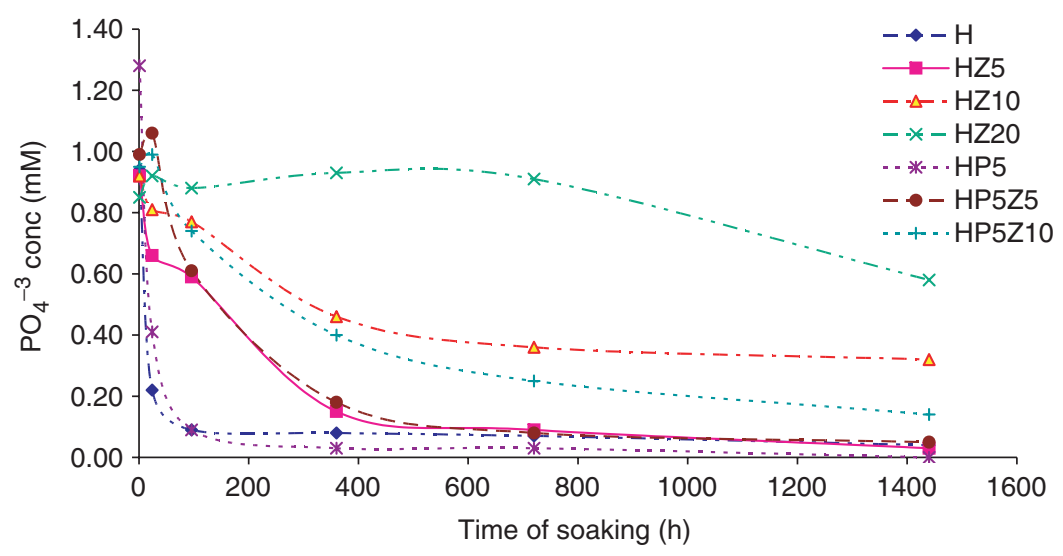

Figure 8. Phosphate concentration in the SBF solution as a function of glass soaking time.

All examined glasses present the same surface to water volume ratio $\left(0.1 \mathrm{~cm}^{-1}\right)$. Particularly interesting is the behavior of the $\mathrm{PO}_{4}^{-3}$ concentration released in solution as a function of the glass composition. Figure 8 shows the total $\mathrm{PO}_{4}^{-3}$ concentration of the solution (total $\mathrm{PO}_{4}^{-3}$ concentration $=$ phosphate concentration of $\mathrm{SBF}$ at $t=0$, plus phosphate concentration due to the glass release) as a function of soaking time. 
A sharp decrease of phosphate concentration is detected for the $\mathrm{H}$ and HP5 glasses during the first 1-4 days, the value dropping near to zero. HZ5 and HP5Z5 glasses show a significant decrement of phosphate concentration after 15 days $(360 \mathrm{~h})$, whereas for the glasses with higher $\mathrm{Zn}$ content a far smaller decrement of phosphate concentration is detected and at longer time with respect to other glasses. The glasses with a high $\mathrm{P}_{2} \mathrm{O}_{5}$ content (HP5 and HP5Z5) release a remarkable quantity of $\mathrm{PO}_{4}^{-3}$ at short exposure times, rapidly increasing the phosphate concentration of SBF ( $1 \mathrm{mM})$.

Zinc concentration detected in the SBF solution is very low (i.e., close to the detection limits of the ICP instrument utilized) for all the glasses studied except for the HZ20 glass at long soaking time (60 days). However, the value measured $(<0.07 \mathrm{mM}=<4.6 \mathrm{ppm})$ is significantly smaller with respect to the average value of $\mathrm{Zn}$ concentration found in human blood plasma (6.4 ppm).

\section{Cell Culture Tests}

Fluorescence micrographs of cell morphology at $3 \mathrm{~h}$ of cell adhesion onto the tested materials are reported in Figure 9. These representative images show cell acceptable adhesion on HZ5 and HP5Z5 (Figure 9(B), (F)) comparable to the control (Figure 9(A)), while low cell spreading is observed on HZ10 (Figure 9(C)) and, particularly, on HZ20 (Figure 9(D)). Furthermore, the effect of high $\mathrm{Zn}$ concentration $(\mathrm{Zn} \%>5)$ has not been modified by the presence of $\mathrm{P}_{2} \mathrm{O}_{5}$.
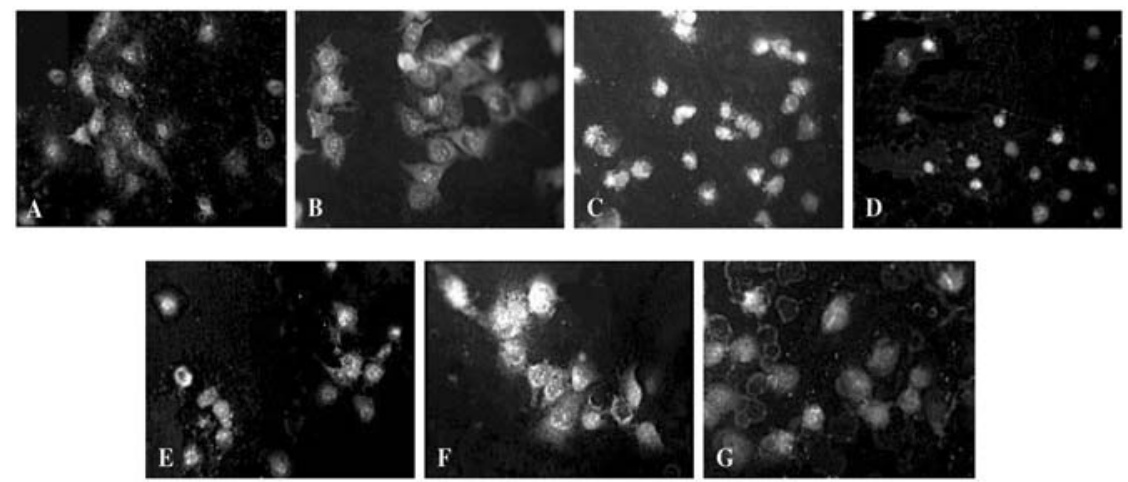

Figure 9. Representative fluorescence microphotographs of Acridine Orange stained MC-3T3 osteoblast cells cultured $3 \mathrm{~h}$ (cell adhesion) on (A) H; (B) HZ5; (C) HZ10; (D) HZ20; (E) HP5; (F) HP5Z5; and (G) HP5Z10. Images at 25× magnification. 
Representative images of cells proliferated onto the same materials are shown in Figure 10. Cell proliferation was comparable to control onto HZ5 and HP5Z5 while it was decreased onto the materials containing higher Zn concentrations.

Results of cell adhesion and proliferation after different incubation times are quantitatively reported in Figure 11 and expressed as meanvalue \pm standard-error of cell number $/ \mathrm{cm}^{2}$. After $3 \mathrm{~h}$, a significantly lower number of cells is present on the material doped with the highest Zn concentration (HZ20). Osteoblast-like cell proliferation on HZ5 was comparable to the control material, while cells cultured on HZ10 and
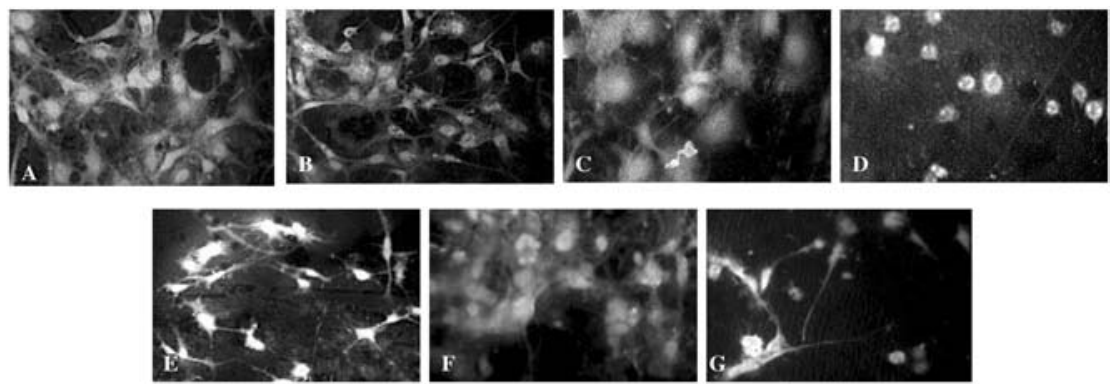

Figure 10. Representative fluorescence microphotographs of Acridine Orange stained MC-3T3 osteoblast cells cultured for 48 h on (A) H; (B) HZ5; (C) HZ10; (D) HZ20; (E) HP5; (F) HP5Z5; and (G) HP5Z10. (Images at magnification 25×).

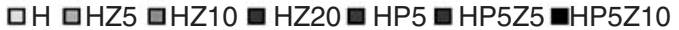

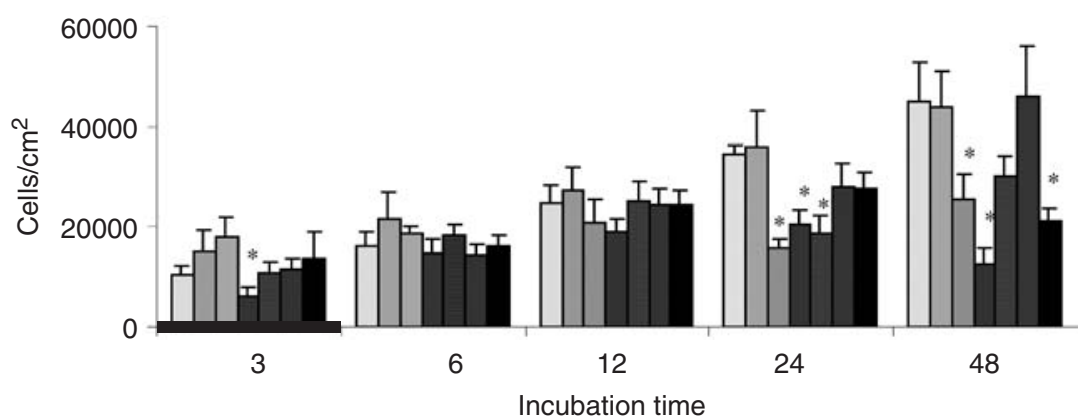

Figure 11. Cell adhesion and proliferation on the different glasses (H; HZ5; HZ10; HZ20; HP5; HP5Z5; HP5Z10) represented as the mean cell number \pm SE of 10 measurements in four experiments $(n=40)$ and referred to a sample surface area of $1 \mathrm{~cm}^{2} .{ }^{*} p<0.05$ with respect to $\mathrm{H}$. 
HZ20 evidenced no increase in cell number after 24-48 h. Also at longer incubation times no differences in cell number have been observed between the materials doped with both $\mathrm{P}_{2} \mathrm{O}_{5}$ and $\mathrm{ZnO}$ and the same materials doped only with $\mathrm{ZnO}$.

\section{Focal Contacts}

After $24 \mathrm{~h}$ contact, cells seeded on bioactive glasses with no $\mathrm{Zn}$ or in presence of a low $\mathrm{Zn}$ percentage (5\%) show a well spread morphology with actin filaments distributed along all the cellular structure (Figure 12).

A large cytoplasmic vinculin labeling is present, as well as the formation of mature adhesion sites close to the cellular membrane. In the presence of a higher percentage of $\mathrm{Zn}(10 \%)$, vinculin is present mainly in the perinuclear site, but no membrane labeling is detected, where focal adhesions are located; in some cases cells are not widely spread on the surface, showing still not organized actin filaments. Cells in contact with HZ20 bioactive glasses do not show vinculin labeling, and the cytoskeleton is totally not organized. In fact, cells show a rounded shape, thus cellular adhesion and spreading are strongly inhibited by the contact with surfaces containing a high $\mathrm{Zn}$ percentage. As the materials doped with $\mathrm{P}_{2} \mathrm{O}_{5}$ and $\mathrm{ZnO}$ do not modify cell behavior having a similar configuration, the authors decided to present only what obtained with Zn-doped bioactive glasses.

\section{Molecular Dynamics Simulations}

Analysis of the structural models obtained by MD simulations for the $\mathrm{H}$ and HP5 glasses shows that the $\mathrm{P}$ ions are preferentially found in isolated tetrahedral units (orthophosphatic units), in agreement with previously published results of ${ }^{31} \mathrm{P}$ MAS NMR [23]. The polymerization degree of the silica network is thus reduced in HP5 with respect to $\mathrm{H}$ glass, and the $\mathrm{Na}$ and $\mathrm{Ca}$ ions are free to move in the silica-rich channels.

Zinc added to H and HP5 glasses co-polymerizes with the Si tetrahedra, increasing the packing of the network with respect to the parent glass. Moreover, $\mathrm{Zn}$ favors the progressive incorporation of $\mathrm{P}$ into the network, forming highly branched strings of interconnected $\mathrm{Si}-\mathrm{Zn}-\mathrm{P}$ tetrahedra.

Segregation zones for the Ca ions are observed in close proximity of $\mathrm{Si}$ and $\mathrm{P}$, whereas a clustering effect of $\mathrm{Na}$ around $\mathrm{Zn}$ tetrahedra is observed. Sodium ions provide compensation for the positive charge 

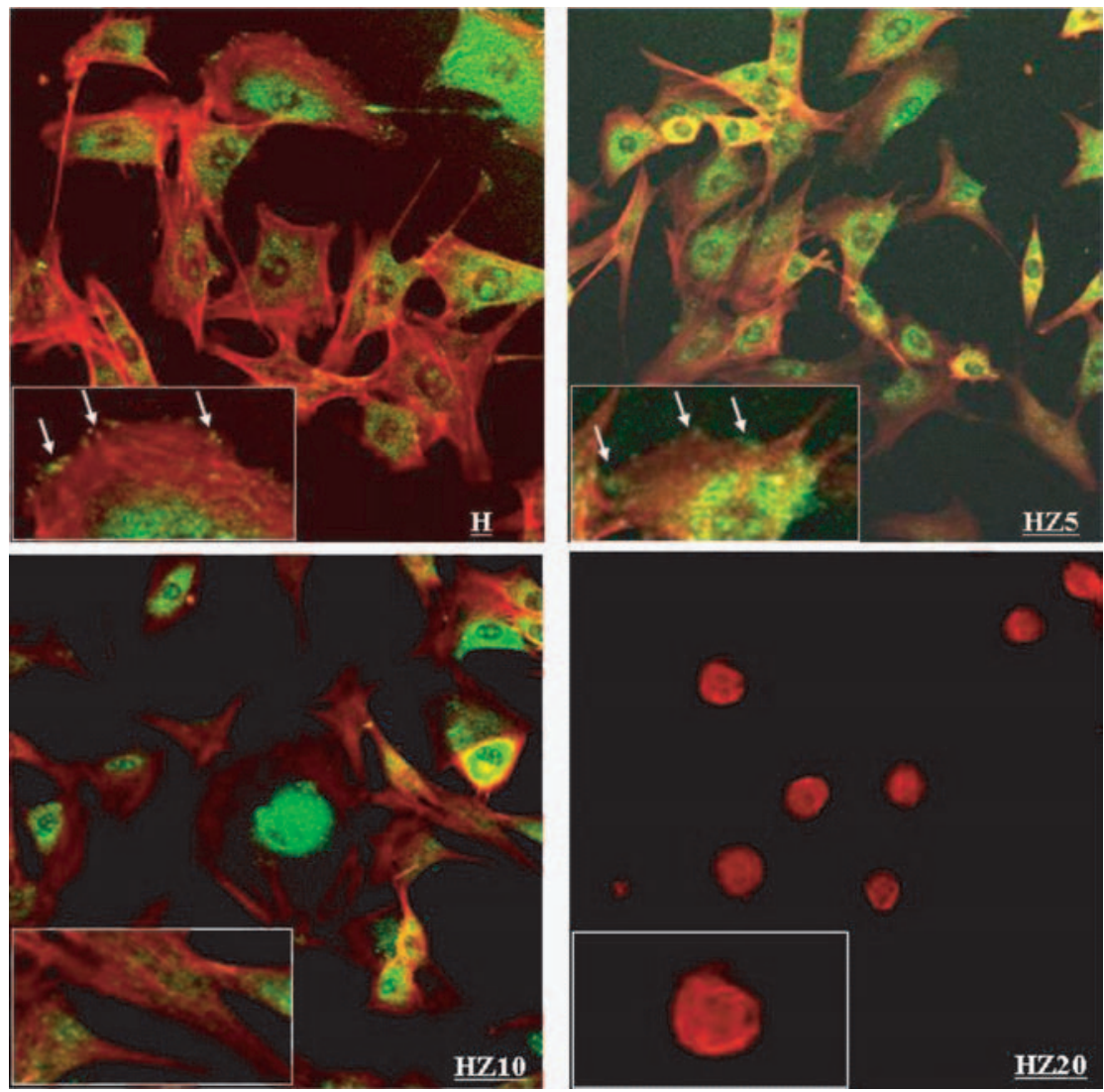

Figure 12. Focal contact formation after $24 \mathrm{~h}$ of seeding onto bioactive glasses doped with different percentages of zinc: 0 (H), 5 (HZ5), 10 (HZ10), and 20 (HZ20) wt\%. Arrows indicate vinculin labeling in presence of focal adhesion sites. (magnification $40 \times$ ).

deficiency of the $\left[\mathrm{ZnO}_{4}\right]^{2-}$ moiety and their mobility within the network is significantly reduced. (Figure 13 ).

\section{DISCUSSION}

In Bioglass ${ }^{\circledR}$ important properties, such as the processing time during clinical applications and implant stability, are limited by the rapid chemical kinetic of the materials conversion for apatite formation. The aim of this work was to identify biocompatible $\mathrm{Zn}$ containing glass formulations with decomposition and conversion rates optimized with respect to the parent Bioglass ${ }^{\circledR}$. 


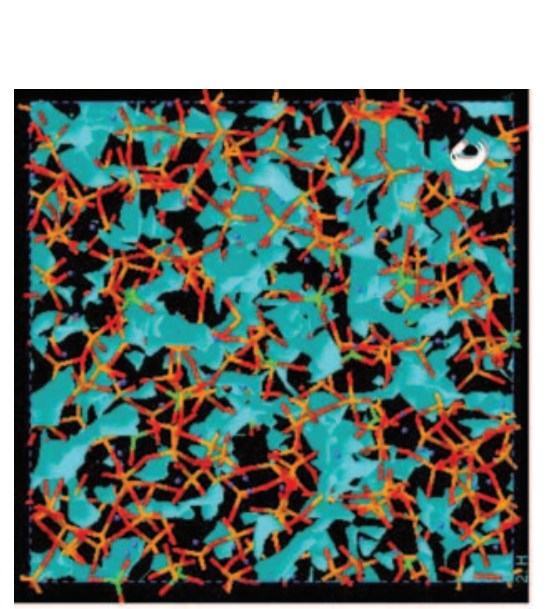

政
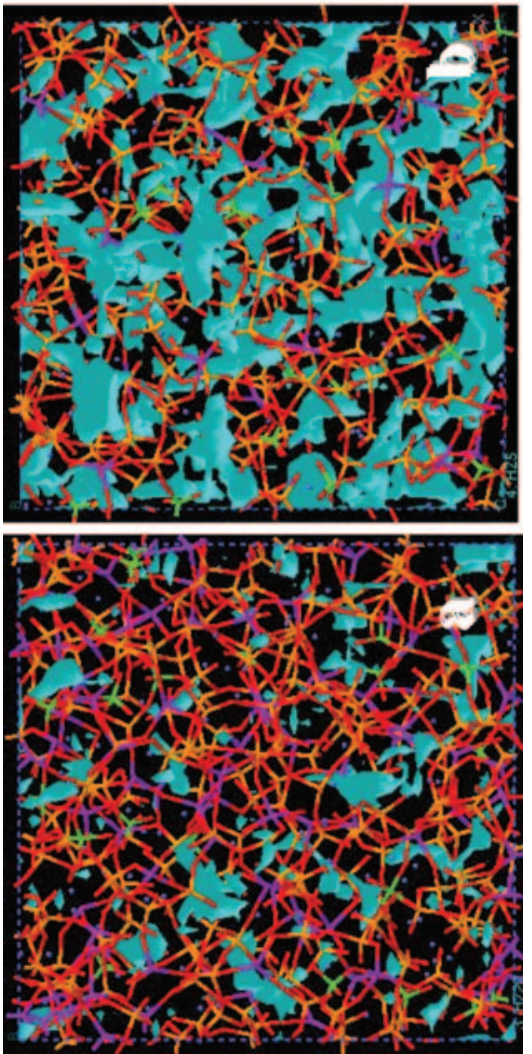

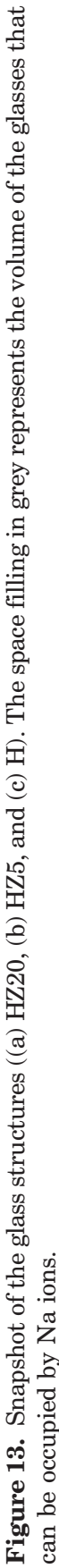


The results obtained show that the rate of reaction in different media is ruled by the amount of $\mathrm{Zn}$ in the glass. In fact, glasses enriched by small amounts of $\mathrm{Zn}$ show dissolution behavior in water and SBF medium similar to $\mathrm{H}$. Analysis of the IR spectra indicate that HZ5 is already reacting even during the first day of soaking in TRIS medium, whereas HZ20 does not show appreciable modifications in the same range of time. The reaction of HZ5 is much slower than that of $\mathrm{H}$ : this is highlighted by the persisting presence of surface Na-carbonates on HZ5 after $6 \mathrm{~h}$ of reaction, whereas Na-carbonates are substituted by $\mathrm{Ca}$-carbonates on the $\mathrm{H}$ glass in the same time range. Scanning electron micrographs on samples soaked in SBF solution reveal spots of HA on the HP5 surfaces already after 4 days of reaction, whereas EDS analysis confirms the presence of a consistent HA layer on the HZ5, HP5, and HP5Z5 surfaces after 15 days of soaking in SBF. Among the samples containing higher concentrations of Zn ions, only HP5Z10 seems to be able to form a HA layer on its surface, although after longer contact time with respect to $\mathrm{H}$.

Accordingly, the results of leaching tests show a sharp decrease of the phosphate concentration in solution for the HP5 and HP5Z5 glasses after 15 days of soaking in SBF. Finally, these glasses manifest an osteoblast-like cell morphology, adhesion, and growth comparable to those of the well known bioactive glass $(\mathrm{H})$, used as reference system, when $\mathrm{Zn}$ concentration added was around $5 \%$. It is possible that high $\mathrm{Zn}$ concentrations (e.g., 20\%) alter the surface chemical-physical characteristics reducing the cell ability to adhere to the surface as demonstrated by the absence of focal contacts observed in the cells seeded onto HZ10 and HZ20 glasses. Moreover, the effect of $\mathrm{Zn}$ released in the cell medium on the cell behavior seems to be negligible as the ions release from the bioglasses was slow and it occurred after different days. Interestingly, the release of $\mathrm{Zn}$ ions from the glasses to the solution is very small even after long soaking time. The results of the MD simulations furnish an invaluable framework for the interpretation of the observed phenomena. The atomistic models obtained show that $\mathrm{Zn}$ is tightly trapped into the silicate network; in fact it copolymerizes with the Si tetrahedra, causing an overall complexation of the network with respect to the parent $\mathrm{H}$ glass. This explains the slow rate of $\mathrm{Zn}$ dissolution into the contacting media and provides insights into the overall reaction rate reduction of the $\mathrm{Zn}$ containing glasses. In fact, the first step of glass degradation, which involves the rapid exchange of $\mathrm{Na}^{+}$with $\mathrm{H}_{3} \mathrm{O}^{+}$ions present in the solution, is hindered by the progressive obstruction of the percolation channels used for the process of $\mathrm{Na}^{+}$ions diffusion into the glasses as a function of $\mathrm{Zn}$ concentration. Moreover, the electrostatic attraction 
exercised by the excess of negative charge on the $\left(\mathrm{ZnO}_{4}\right)^{2-}$ tetrahedral restrains further the $\mathrm{Na}^{+}$ions mobility. Therefore, high concentrations of $\mathrm{Zn}$ seem to be responsible for the drastic reduction in the overall leaching activity of the HZ20 glass and of its inability to form HA. These effects are partially attenuated by the introduction in the glass of higher percentages of $\mathrm{P}_{2} \mathrm{O}_{5}$ with respect to the $\mathrm{H}$ glass. In fact, being $\mathrm{P}$ usually found in isolated tetrahedra, it tends to depolymerize the network antagonizing [24] the Zn effect. However, by increasing Zn concentration, $\mathrm{P}$ is progressively incorporated into the network and highly branched chains of interconnected $\mathrm{Si}-\mathrm{Zn}-\mathrm{P}$ tetrahedra are formed, affecting glass solubility and HA formation ability.

\section{CONCLUSIONS}

The results of molecular simulation studies, corroborated by in vitro observations in an acellular medium, indicate that the HZ5, HP5Z5, and HP5Z10 glasses manifest the pre-requisites for bioactivity, since they are able to form a hydroxy-carbonate-apatite layer on their surface after soaking in SBF solution. Moreover, cell culture tests with MC-3T3 osteoblast cells, and a not significant change of response regarding the focal contacts, allowed the authors to select the HZ5 and HP5Z5 glasses as the ones having an optimal $\mathrm{Zn} / \mathrm{P}$ ratio to maintain cell adhesion and cell growth comparable to those of the parent bioglass $(\mathrm{H})$ used as a control.

\section{ACKNOWLEDGMENTS}

This work was supported by Ministero dell'Università' e della Ricerca Scientifica e Tecnologica, (MIUR, grant 2003032158_005).

\section{REFERENCES}

1. Hench, L.L. (1998). Bioactive Materials: The Potential for Tissue Regeneration, Biomaterials, 19(16): 1419-1423.

2. Hench, L.L., Splinter, R.J., Allen, W.C. and Greenlee Jr, T.K. (1972). Bonding Mechanisms at the Interface of Ceramic Prosthetic Materials, J. Biomed. Mater. Res., 2: 117-141.

3. Vallet-Regì, M. (2001). Ceramics for Medical Applications, J. Chem. Soc., Dalton Trans., 2: 97-108.

4. Ito, A., Ojima, K., Naito, H., Ichinose, N. and Tateishi, T. (2000). Preparation, Solubility, and Cytocompatibility of Zinc-releasing Calcium Phosphate Ceramics, J. Biomed. Mater. Res., 50(2): 178-183. 
5. Ito, A., Kawamura, H., Otsuka, M., Ikeuchi, M., Ohgushi, H., Ishikawa, K., Onuma, K., Kanzaki, N., Sogo, Y. and Ichinose, N. (2002). Zinc-releasing Calcium Phosphate for Stimulating Bone Formation, Material Science and Engineering, 22: 21-25.

6. Yamaguchi, M. and Yamaguchi, R. (1986). Action of Zinc on Bone Metabolism in Rats Increases in Alkaline Phosphatase Activity and DNA Content, Biochem. Pharmacol., 35: 773-777.

7. Kanno, S., Anuradha, C.D. and Hirano, S. (2001). Localization of Zinc After in vitro Mineralization in Osteoblastic Cells, Biol. Trace Elem. Res., 83(1): 39-47.

8. Kanno, S., Anuradha, C.D. and Hirano, S. (2001). Chemotactic Responses of Osteoblastic MC3T3-E1 Cells toward Zinc Chloride, Biol. Trace Elem. Res., 83(1): 49-55.

9. Söderholm, K.J.M., Mondragon, E. and Garcea, I. (2003). Use of Zinc Phosphate Cement as a Luting Agent for Denzir ${ }^{\mathrm{TM}}$ Copings: An in vitro Study, BMC Oral Health, 3: 1-8.

10. Linati, L., Lusvardi, G., Malavasi, G., Menabue, L., Menziani, M.C., Mustarelli, P. and Segre, U. (2005). Qualitative and Quantitative Structure-Property Relationships (QSPR) Analysis of Multicomponent Potential Bioglasses, J. Phys. Chem. B, 109: 4989-4998.

11. Lusvardi, G., Malavasi, G., Menabue, L., Menziani, M.C., Pedone, A. and Segre, U. (2005). A Computational Tool for the Prediction of Crystalline Phases Obtained from Controlled Crystallization of Glasses, J. Phys. Chem. $B$, 109: 21586-21592.

12. Lusvardi, G., Malavasi, G., Menabue, L., Menzioni, M.C., Segre, U., Carnasciali, M.M. and Ubaldini, A. (2004). A Combined Experimental and Computational Approach to $\left(\mathrm{Na}_{2} \mathrm{O}\right)_{1-\mathrm{x}} \cdot \mathrm{CaO} \cdot(\mathrm{ZnO})_{\mathrm{X}} \cdot 2 \mathrm{SiO}_{2}$ Glasses Characterization, J. Non-Cryst. Solids, 345: 710-714.

13. Oki, A., Parveen, B., Hossain, S., Adeniji, S. and Donahue, H. (2004). Preparation and in vitro Bioactivity of Zinc Containing Sol-gel-derived Bioglass Materials, Journal of Biomedical Materials Research Part A, 69(2): 216-221.

14. Kokubo, T., Kushitani, H., Sakka, S., Kitsugi, T. and Yamamuro, T. (1990). Solutions Able to Reproduce in vivo Surface-structure Changes in Bioactive Glass-ceramic, J. Biomed. Mater. Res., 24: 721-734.

15. Lusvardi, G., Malavasi, G., Menabue, L. and Menziani, M.C. (2002). Synthesis, Characterization and Molecular Dynamics Simulation of $\mathrm{Na}_{2} \mathrm{O}-\mathrm{CaO}-\mathrm{SiO}_{2}-\mathrm{ZnO}$ Glasses, J. Phys. Chem. B, 106: 9753-9760.

16. Brunauer, S., Emmet, P.H. and Teller, E.J. (1938). Adsorption of Gases in Multimolecular Layers, J. Am. Chem. Soc., 60: 309-319.

17. Kepner, R.L. and Pratt, J.R. (1994). The Use of Fluyorochromes for Direct Enumeration of Total Bacteria in Enviromental Samples: Past and Present, Microbiol. Rev., 58: 603-615.

18. Smith, W. and Forester, T.R. (1996). DL_POLY 2.0. A General Purpose Parallel Molecular Dynamics Package, J. Mol. Graphics, 14: 136.

19. Cerius $2^{\circledR}$ (2001). Accelrys, Inc., San Diego, CA. 
20. Cormack, A.N. and Cao, Y. (1996). Molecular Dynamics of Silicate Glasses, Mol. Eng., 6: 183-227.

21. Vessal, B. (1994). Simulation Studies of Silicates and Phosphates, J. NonCryst. Solids, 177: 103-124.

22. Cerruti, M. and Morterra, C. (2004). Carbonate Formation on Bioactive Glasses, Langmuir, 20: 6382-6388.

23. Canevali, C., Mattoni, M., Morazzoni, F., Scotti, R., Casu, M., Musinu, A., Polizzi, S., Speghini, A. and Bettinelli, M. (2005). Stability of Luminescent Trivalent Cerium in Silica Host Glasses Modified by Boron and Phosphorous, J. Am. Chem. Soc., 127(42): 14681-14691.

24. Jensen, T.R., Gerentes, N., Jepsen, J., Hazell, R.G. and Jakobsen, H.J. (2005). New Amine-templated Zinc Phosphates with a Temperature-induced Increase of Structural Dimensionality, Inorg. Chem., 44(3): 658-665. 